\title{
Induction of Indoleamine 2,3-dioxygenase (IDO) Enzymatic Activity Contributes to Interferon-Gamma Induced Apoptosis and Death Receptor 5 Expression in Human Non-small Cell Lung Cancer Cells
}

\author{
Ting Wen Chung ${ }^{1,2}$, Kok-Tong Tan ${ }^{3,4}$, Hong-Lin Chan ${ }^{2}$, Ming-Derg Lai ${ }^{5}$, Meng- \\ Chi Yen ${ }^{5}$, Yi-Ron $\mathrm{Li}^{4}$, Sheng Hao Lin ${ }^{1,4}$, Chi-Chen Lin ${ }^{1,4,6,7 *}$
}

\begin{abstract}
Interferon-gamma (IFN- $\gamma$ ) has been used to treat various malignant tumors. However, the molecular mechanisms underlying the direct anti-proliferative activity of IFN- $\gamma$ are poorly understood. In the present study, we examined the in vitro antitumor activity of IFN- $\gamma$ on two human non-small-cell lung carcinoma (NSCLC) cell lines, H322M and H226. Our findings indicated that IFN- $\gamma$ treatment caused a time-dependent reduction in cell viability and induced apoptosis through a FADD-mediated caspase-8/tBid/mitochondria-dependent pathway in both cell lines. Notably, we also postulated that IFN- $\gamma$ increased indoleamine 2,3-dioxygenase (IDO) expression and enzymatic activity in H322M and $\mathrm{H} 226$ cells. In addition, inhibition of IDO activity by the IDO inhibitor 1-MT or tryptophan significantly reduced IFN- $\gamma$-induced apoptosis and death receptor 5 (DR5) expression, which suggests that IDO enzymatic activity plays an important role in the anti-NSCLC cancer effect of IFN- $\gamma$. These results provide new mechanistic insights into interferon- $\gamma$ antitumor activity and further support IFN- $\gamma$ as a potential therapeutic adjuvant for the treatment of NCSLC
\end{abstract}

Keywords: Non-small-cell lung carcinoma - nterferon- $\gamma$ - apoptosis - indoleamine 2,3-dioxygenase - death receptor 5

Asian Pac J Cancer Prev, 15 (18), 7995-8001

\section{Introduction}

Lung cancer is the most common cancer in terms of both incidence and mortality worldwide. Among lung cancers, non-small cell lung carcinomas (NSCLC) account for approximately $80 \%-85 \%$ of lung cancer cases (Mitsudomi, 2010; Cancer, 2014). Despite improvements in survival through early detection and treatment of NSCLC, many patients suffer from rapid disease recurrence and progression (Xu et al., 2012; Zheng et al., 2013; Sun et al., 2014). Therefore, the search for new or alternative therapeutic approaches remains important and urgently needed in clinical cancer therapeutics.

Interferon gamma (IFN- $\gamma$ ) is a pleiotropic cytokine with diverse physiological functions. IFN- $\gamma$ is a major activator of various types of immune cells (Wakita et al., 2009; Hayakawa et al., 2011) and also can induce the expression of the major histocompatibility complex in both normal and malignant cells and provokes inflammatory infiltrate infiltration (Chen et al., 2012; Hong et al., 2014). In addition, IFN- $\gamma$ can directly inhibit the growth of cells, in some cases, through the induction of cell cycle arrest with or without the concomitant induction of apoptosis (Tate et al., 2012; Liu et al., 2012; Jin et al., 2013; Zhao et al., 2013 Wang, 2014). Recognition of the direct antiproliferative properties of IFN- $\gamma$ and its ability to stimulate the immune system has led to the investigation of its therapeutic activity in a number of malignant conditions.

IFN- $\gamma$ has been used in treating patients with advanced NSCLC, and the results from these initial small clinical studies suggest that IFN- $\gamma$ can mediate a measurable antitumor effect in vivo (Mattson et al., 1991). In addition, for patients with advanced NSCLC, an adjunctive dose of $100 \mu \mathrm{g}$ IFN- $\gamma$, given three times weekly in the induction and maintenance phase, is feasible. Survival data seem favorable; thus, this regimen may warrant further investigation in a phase III study (Prior et al., 1999). However, the mechanisms of action of IFN- $\gamma$ in NSCLC

${ }^{1}$ Division of Chest Medicine, Department of Internal Medicine, Changhua Christian Hospital, Changhua, ${ }^{2}$ Institute of Bioinformatics and Structural Biology and Department of Medical Sciences, National Tsing Hua University, Hsinchu, ${ }^{3}$ Tungs' Taichung MetroHarbor Hospital, ${ }^{4}$ Institute of Biomedical Sciences, College of Life Science, ${ }^{6}$ Rong Hsing Research Center for Translational Medicine, National Chung Hsing University, ${ }^{7}$ Department of Medical Research and Education, Taichung Veterans General Hospital, Taichung, ${ }^{5}$ Department of Biochemistry and Molecular Biology, National Cheng-Kung University, Tainan, Taiwan *For correspondence: lincc@dragon.nchu.edu.tw 
Ting Wen Chung et al

are merely speculative. Thus, the present study aimed to elucidate the direct effect of IFN- $\gamma$ on cell growth in $\mathrm{H} 322 \mathrm{M}$ and $\mathrm{H} 226$ human NSCLC cells and to investigate the detailed mechanism of its anti-cancer activity.

\section{Materials and Methods}

\section{Cell Culture and Reagents}

The human non-small cell lung carcinoma cells, A549 (adenocarcinoma), H226 (squamous cell carcinoma) and H322M (bronchi alveolar carcinoma) were obtained from Dr. Jeremy J.W. Chen at Chung Hsing University. The cells were grown in RPMI 1640 medium (GIBCO/ Life Technologies) containing $10 \%$ fetal bovine serum (FBS, GIBCO/Life Technologies), $100 \mathrm{U} / \mathrm{ml}$ penicillin and streptomycin Recombinant human IFN- $\gamma$ (R\&D) was prepared a $100 \mathrm{mg} / \mathrm{ml}$ stock solution in PBS, stored at $-80^{\circ} \mathrm{C}$ until use.

\section{Cell viability assay}

Cells were seeded into 24-well tissue culture plates and treated with IFN- $\gamma$ at various concentrations (0$100 \mathrm{ng} / \mathrm{ml})$ for the indicated time, and the cell viability was determined by 3-(4,5-dimethylthiazolyl-2)-2, 5-diphenyltetrazoliumbromide (MTT) assay (SigmaAldrich Co.).

\section{Cell cycle analysis}

Cells were treated with IFN- $\gamma$ for the indicated time point. Harvested cells were then washed with PBS and fixed in $70 \%$ ethanol at $-20^{\circ} \mathrm{C}$ for overnight. The fixed cells were stained in solution containing RNase A (50 $\mu \mathrm{g} / \mathrm{ml}$ Sigma-Aldrich Co.) and propidium iodide (PI, $50 \mathrm{mg} / \mathrm{ml}$, Sigma-Aldrich Co.) in the dark for $30 \mathrm{~min}$ at room temperature. Flow cytometry was performed using a FACSCalibur flow cytometry (FACSCalibur; BD BioSciences).

\section{Measurement of mitochondrial membrane potential (MMP)}

Changes in mitochondrial membrane potential were examined by flow cytometry using JC-1 (Molecular Probes). For this assay, cells were treated with IFN$\gamma$ for the indicated time point. Ten minutes prior to flow cytometry analysis, JC- 1 was added to a final concentration $10 \mu \mathrm{g} / \mathrm{ml}$ at $37^{\circ} \mathrm{C}, 5 \% \mathrm{CO}_{2}$ atmosphere. At the design time, cell were analyzed for each treatment group on a FL-1 $(530 \mathrm{~nm})$ versus FL-2 $(580 \mathrm{~nm})$ dot plot on a flow cytometer (FACSCalibur, BD BioSciences).

\section{Western blot analysis}

Cells were solubilized in cell lysis buffer (Cell signaling). Lysates were clarified by centrifugation, and protein concentrations were measured using the BCA Protein Assay Reagent (PIERCE). Cell lysates were resolved by electrophoresis using a SDS-polyacrylamide gel (12 or $15 \%)$ and electrophoretically transferred to a PVDF membrane. The membranes were blocked at room temperature for $1 \mathrm{~h}$ in $5 \%$ non-fat milk and blotted with primary antibodies against phospho-STAT1, STAT1, caspase-3, caspase-8, caspase-9, Bax, Bcl-2,
Bcl-Xl, Bak, truncated Bid, and cleaved PARP (all from cell signaling) and IDO (Santa Cruz) at $4{ }^{\circ} \mathrm{C}$ overnight, followed by secondary antibodies linked to HRP (The Jackson Laboratory) for 2 hours. The immunoactive bands were detected with the enhanced chemiluminescence (ECL) system and developed using the LAS3000 system (Fujifilm, Japan).

\section{In vitro assay for cytochrome c release}

Cells were treated with $100 \mathrm{ng} / \mathrm{ml}$ IFN- $\gamma$ for 96 hr. Harvested cells were collected by centrifugation. Cytosolic fractions were isolated using the Mitochondria/ Cytosol Fraction Kit (BioVision). The quality of the cytosolic fraction was then determined by western blotting using an anti-cytochrome c antibody (BD Pharmingen).

\section{Transient transfection and RNA interference}

Cells were transiently transfected with 400 pmol of FADD siRNA (Santa Cruz) using the Lipofectamine 2000 reagent. Twenty-four hours after transfection, cells were treated $10 \mathrm{ng} / \mathrm{ml}$ concentration of IFN- $\gamma$ for the indicated time. The cell viability was examined by MTT assay.

\section{IDO enzymatic activity assay}

Cells were treated with different doses of IFN- $\gamma$.At the indicated time point, the cells were disrupted by three freeze/thaw cycles in $200 \mu \mathrm{L}$ of PBS buffer, and the lysates was cleared by centrifugation at $3000 \times \mathrm{g}$. An equal amount of $2 \times$ IDO assay buffer (potassium phosphate buffer (100 $\mathrm{mmol} / \mathrm{L}, \mathrm{pH} 6.5)$, ascorbic acid (40 $\mathrm{mmol} / \mathrm{L}$, neutralized with $\mathrm{NaOH})$, catalase $(400 \mu \mathrm{g} / \mathrm{mL})$, methylene blue $(20$ $\mu \mathrm{mol} / \mathrm{L})$, and L-tryptophan $(800 \mu \mathrm{mol} / \mathrm{L}$; all reagents were purchased from sigma-Aldrich) was added. After 45 min incubation at $37{ }^{\circ} \mathrm{C}$, the reaction was stopped with the addition of $20 \mu \mathrm{l}$ of $30 \% \mathrm{w} / \mathrm{v}$ trichloroacetic acid at $65^{\circ} \mathrm{C}$ for an additional $15 \mathrm{~min}$, and the reaction mixture was centrifuged at $6000 \times \mathrm{g}$ for $5 \mathrm{~min}$. After centrifugation, $20 \mu \mathrm{l}$ of supernatant was analyzed by a high performance liquid chromatography system with a reverse-phase column (Mightysil RP-18 GP 4.6×250 mm; Kanto Chemical Co. Inc.). L-Kynurenine (5-100 $\mu \mathrm{mol} / \mathrm{L}$, sigma) was used as the standard.

Analysis of death receptors and ligands by flow cytometry After IFN- $\gamma$ treatment at indicated times, the cells were suspended in FACS buffer (PBS supplemented with $5 \% \mathrm{FBS}$ and $0.1 \% \mathrm{NaN} 3$ ) and then incubated with antiDR4-PE, anti-DR5-PE, and anti-Fas-PE, (eBioscience) at $4^{\circ} \mathrm{C}$ for $30-45$ minutes. Subsequently, the stained cells were fixed with $1 \%$ paraformaldehyde (Sigma), and the expression level of each molecule was analyzed by flow cytometry.

\section{IDO inhibitor (1-MT) and tryptophan treatment assay}

The cells were pre-treated with IDO inhibitors of 1-methyl-tryptophan 1-MT (sigma) or L-tryptophan for $1 \mathrm{hr}$ and then treated with $10 \mathrm{ng} / \mathrm{ml} \mathrm{IFN}-\gamma$ for $96 \mathrm{~h}$. The treated cells were subjected to MTT assay, flow cytometry analysis following staining with Annexin V-FITC and propidium iodide (PI) or western blotting assay. 


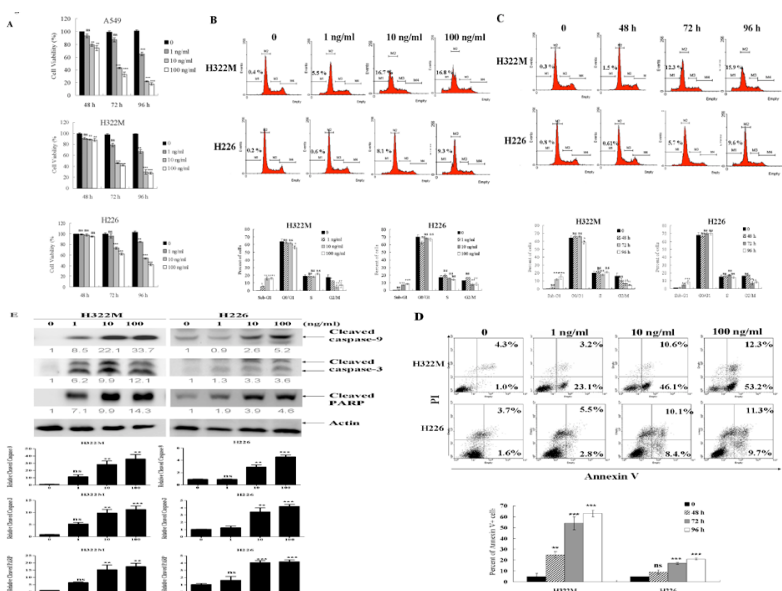

Figure 1. IFN- $\gamma$ reduced cell viability and apoptosis in NSCLC cells. (A) Cells were treated with different concentrations of IFN- $\gamma(0-100 \mathrm{ng} / \mathrm{ml})$ for $48-96 \mathrm{~h}$ and subjected to MTT assay. The viability of PBS-treated cells was considered $100 \%$. (B) Cells were treated with different concentration of IFN- $\gamma(0-100 \mathrm{ng} / \mathrm{ml})$ for 96 $\mathrm{h}$ or (C) $10 \mathrm{ng} / \mathrm{ml} \mathrm{IFN}-\gamma$ for $48-96 \mathrm{~h}$ and subject to cell cycle analysis. (D) Cells were treated with different concentrations of IFN- $\gamma(0-100 \mathrm{ng} / \mathrm{ml})$ for $96 \mathrm{~h}$ and subject to Annexin V/PI staining. (E) Cells were treated with different concentrations of IFN- $\gamma(0-100 \mathrm{ng} / \mathrm{ml})$ for $96 \mathrm{~h}$. Total cell lysates were prepared to detect the cleaved forms of caspase-9, caspase- 3 and PARP. The bands were analyzed by ImageJ and normalized to actin. The means \pm SD of the experimental triplicates are presented in the bar graph. All data presented are representatives of three independent experiments with similar results. $\mathrm{nsp}>0.05, * p<0.05, * * p<0.01, * * * p<0.001$, compared with the PBS-treated group

\section{Statistical Analysis}

The results are expressed as the mean \pm SD. Statistical analyses were performed by one-way ANOVA followed by Tukey's post-hoc test. A $p<0.05$ was considered statistically significant.

\section{Results}

\section{IFN- $\gamma$ inhibits the growth of NSCLC cell lines}

To study the anti-proliferative effect of IFN- $\gamma$ on human Non-small-cell lung carcinoma (NSCLC) cell, three NSCLC cell lines, A549, H322M and H226, were chosen. The cells were treated with various concentrations of IFN- $\gamma$ to investigate the cytotoxicity of IFN $-\gamma$ against these cells. Cell viability was then examined using the MTT assay. IFN- $\gamma$ inhibited cell growth in a dose- and time-dependent manner in all three cell lines (Figure 1A). However, the growth of A549 and H322M cell lines were inhibited to a greater extent than the growth of $\mathrm{H} 226$ cells.

\section{IFN- $\gamma$ induces apoptosis in in H322M and H226 cells}

Furthermore, to determine whether IFN- $\gamma$-induced growth inhibition occurs via cell cycle blockade or apoptosis, H322M and H226 cells were assayed using PI staining and subjected to flow cytometric analysis. Figure $1 \mathrm{~B}$ and $1 \mathrm{C}$ show that IFN- $\gamma$ treatment did not cause cycle
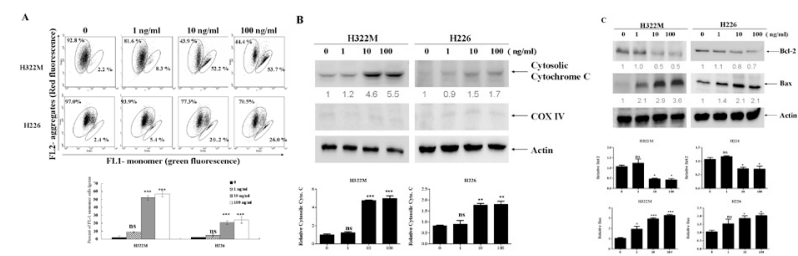

Figure 2. IFN- $\boldsymbol{\gamma}$ triggered mitochondrial apoptotic events in H322M and $\mathbf{H 2 2 6}$ cells. Cells were treated with different concentration of IFN- $\gamma(0-100 \mathrm{ng} / \mathrm{ml})$ for $96 \mathrm{~h}$ and (A) subject to JC-1 fluorescence staining and (B) Immunoblotting for cytochrome c using cytosolic fractions. Blots were stripped and reprobed with cytochrome c oxidase subunit IV (COX IV) as a mitochondrial marker. (C) Total cell lysates were prepared and subjected to western blot with antibodies to detect the expression of Bcl-2 and Bax, The bands were analyzed by ImageJ and normalized to actin. The means \pm SD of the three independent experiments are presented in the bar graph. All data shown are representatives of three independent experiments with similar results. $\mathrm{nsp}>0.05$, ${ }^{*} p<0.05,{ }^{*} p<0.01,{ }^{*} * *<<0.001$, compared with the PBS -treated group.

arrest during the 48 to $96 \mathrm{hr}$ period. However, the sub-G1 population, which is typically considered an apoptosis, significantly increased in a dose- and time-dependent manner after IFN- $\gamma$ treatment. To further examine the observed IFN- $\gamma$-induced apoptosis, we utilized flow cytometry following staining with annexin V-FITC. As presented in Figure 1D, the percentages of early apoptotic death (Annexin V+/PI-) increased in a dose-dependent manner, suggesting that IFN $-\gamma$ predominantly induced apoptosis in H322M and $\mathrm{H} 226$ cells. This result was confirmed by analyzing the level of cleaved caspase-9, caspase-3 and PARP after IFN- $\gamma$ treatment (Figure 1E).

IFN- $\gamma$ activates the mitochondria-mediated apoptotic pathway in H322M and H226 cells

Mitochondria play an important role in the intrinsic and extrinsic apoptotic death pathways (Sankari et al., 2012; Wang et al., 2014). Loss of mitochondrial membrane potential $(\Delta \psi \mathrm{m})$ is an indicator of mitochondrial damage during apoptosis. The $\Delta \Psi \mathrm{m}$ was estimated using JC-1 fluorescent dye by flow cytometry. In healthy cells with high $\Delta \Psi \mathrm{m}, \mathrm{JC}-1$ incorporates into mitochondria and forms aggregates (fluorescence in red, $590 \mathrm{~nm}$ ). However, in apoptotic or unhealthy cells with low $\Delta \Psi \mathrm{m}, \mathrm{JC}-1$ incorporates into mitochondria and forms monomers (fluorescence in green, $527 \mathrm{~nm}$ ) (Smiley et al., 1991). As shown in Figure 2A, treatment of H322M and H226 cells with IFN- $\gamma$ for $96 \mathrm{~h}$ led to a dose-dependent increase in red fluorescence relative to the PBS-control group, suggesting that IFN- $\gamma$ treatment led to a reduction in $\Delta \psi \mathrm{m}$. In addition, the release of cytochrome $\mathrm{c}$ from the mitochondria into the cytosol is a key initiative step in the mitochondrial apoptotic pathway. The Bcl-2 family is known for its ability to target mitochondria and induce cytochrome c release (Kluck et al., 1997; Wang et al., 2014). As shown in Figure 2B, IFN- $\gamma$ induced an increase in the level of cytosolic cytochrome c in H322M and H226 cells. In addition, western blot analysis revealed 

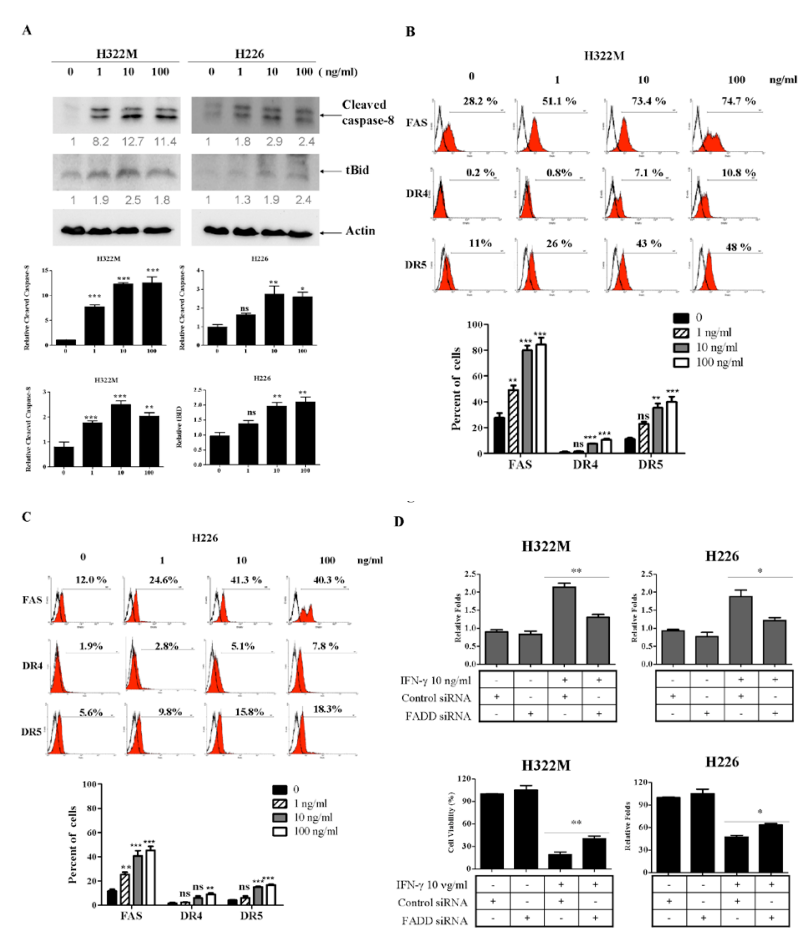

Figure 3. IFN- $\gamma$ induced the activation of the FADD/ caspase-8-tBid cascade and up-regulated death receptor expression in $\mathrm{H322M}$ and $\mathrm{H} 226$ cells. Cells were treated with different concentrations of IFN- $\gamma$ for 96 h. (A) Total cell lysates were prepared to detect the cleaved caspase- 8 and tBid. The bands were analyzed by Image J and normalized to actin. (B) The expression of FAS, DR, and DR5 receptor surface expression in H322M and (C) H226 were examined by flow cytometry after staining with respective PE-conjugated antibodies. (D) After transfection of negative control siRNA or FADD-siRNA for $24 \mathrm{~h}$, FADD protein expression was determined with real time PCR. The effect of $10 \mathrm{ng} / \mathrm{ml}$ IFN- $\gamma$ treatment on cell viability was detected by MTT assay for $72 \mathrm{~h}$. Data are the mean \pm SD of triplicate wells. All data shown are representatives of three independent experiments with similar results. nsp $>0.05, * p<0.05$, $* * p<0.01, * * * p<0.001$ compared with the PBS-treated group. $\# p<0.001$, compared with the $10 \mathrm{ng} / \mathrm{ml}$ IFN- $\gamma$ treated group.

that the anti-apoptotic protein $\mathrm{Bcl}-2$ was down-regulated and that the pro-apoptotic protein Bax was up-regulated (Figure 2C). Taken together, these findings suggest that treatment with IFN- $\gamma$ induces apoptosis primarily through the mitochondrial apoptosis pathway.

IFN- $\gamma$ increases caspase-8 activity and death receptor expression in $\mathrm{H} 322 \mathrm{M}$ and $\mathrm{H} 226$ cells

Active caspase- 8 can induce the mitochondrial apoptotic pathway by cleaving Bid, freeing the truncated form to translocate to the mitochondria, which leads to mitochondria damage and activates mitochondrial apoptotic downstream signals, including cytochrome c release into the cytosol (Sankari et al., 2012; Tao et al., 2012). As shown in Figure $3 \mathrm{~A}$, IFN- $\gamma$ treatment could dose independently increases the level of cleaved caspase- 8 protein and truncated $\mathrm{Bid}$. In addition, the death receptor

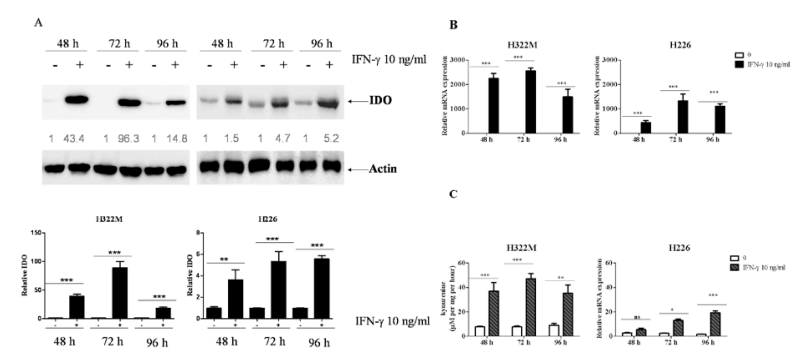

Figure 4. IFN- $\gamma$ induced IDO expression and activity in H322M and $\mathrm{H} 226$ cells. Cells were treated with $10 \mathrm{ng} /$ $\mathrm{ml}$ IFN- $\gamma$ for the indicated time. (A) Total cellular protein was extracted, and the IDO expression was determined by western blot analysis. The bands were analyzed by ImageJ and normalized to actin. (B) Total RNA was extracted, and the IDO mRNA expression levels were measured by quantitative real-time RT-PCR. (C) IDO enzymatic activity was measured as the concentrations of L-kynurenine as detected through HPLC. Data are presented as the mean $\pm \mathrm{SD}$ of triplicate wells. All data shown are representatives of three independent experiments with similar results. nsp $>0.05,{ }^{*} p<0.05$, $* * p<0.01, * * * p<0.001$ compared with the PBS-treated group

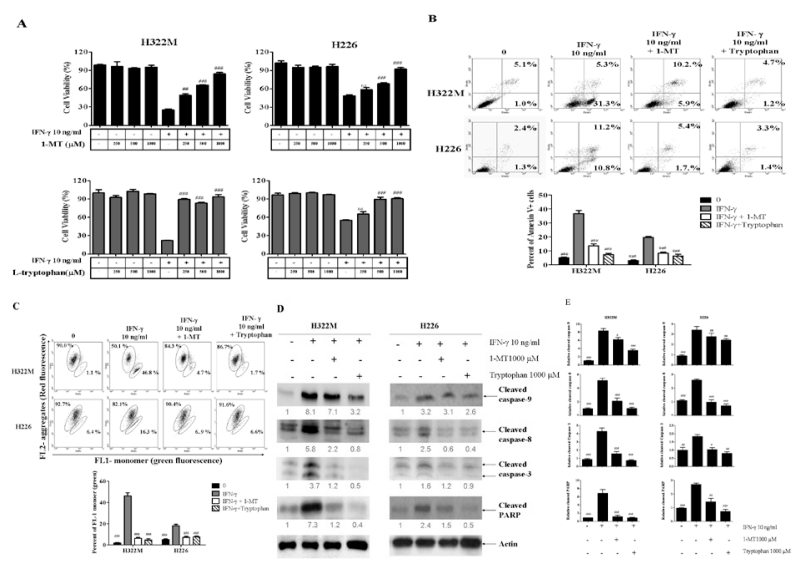

Figure 5. Inhibition of IDO activity reduces IFN$\gamma$-induced apoptosis in $\mathrm{H322M}$ and $\mathrm{H} 226$ cells. (A) Cells were treated with $10 \mathrm{ng} / \mathrm{ml}$ IFN- $\gamma$ alone or in combination with the IDO inhibitor 1-MT (250-100 $\mu \mathrm{M})$ or L- tryptophan (250-100 $\mu \mathrm{M})$ for $96 \mathrm{~h}$, and viability was assessed using the MTT assay. The cells were stained with (B) annexin V-FITC/propidium iodide (PI) or (C) JC-1, and flow cytometry analysis was used to detect cell apoptosis and mitochondrial membrane potential. (D) Cleaved Caspase-8, Caspase-9, caspase- 3 and PARP levels were assessed by western blot analysis. The bands were analyzed by ImageJ and normalized to actin. All data are presented as the mean \pm SD of triplicate wells. The figure was representatives of three independent experiments with

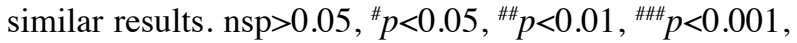
compared with the IFN- $\gamma$-treated group.

signaling complex (DISC) formation results in the activation of caspase-8, which plays the important role in cell apoptosis. In particular, the DR4/5 and Fas receptors and their ligands have been extensively investigated (Guo et al., 2012; Hong et al., 2013). As shown in Figure 3B and $3 \mathrm{C}$, the expression of Fas and DR5 significantly increased 


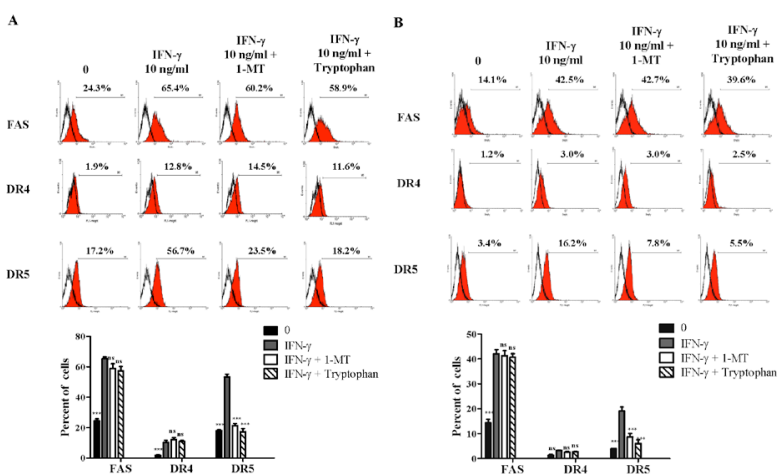

Figure 6. Inhibition of IDO activity reduces IFN- $\gamma$ induced death receptor 5 expression in $\mathrm{H322M}$ and H226 cells. Cells were treated with $10 \mathrm{ng} / \mathrm{ml} \mathrm{IFN}-\gamma$ alone or in combination with the IDO inhibitor 1-MT (1000 $\mu \mathrm{M})$ or L-tryptophan $(1000 \mu \mathrm{M})$ for $96 \mathrm{~h}$. The expression of FAS, DR, and DR5 receptor surface expression in A) H322M and B) H226 was examined by flow cytometry after staining with the respective PE-conjugated antibodies. The mens \pm SD of the experimental triplicates are presented in the bar graph. nsp $>0.05,{ }^{\# \#} p<0.001$, compared with the IFN- $\gamma$-treated group.

in a time-dependent pattern after IFN- $\gamma$ treatment in $\mathrm{H} 322 \mathrm{M}$ and H226 cells. Moreover, given that activated death receptors recruit an adaptor protein called FasAssociated Death Domain (FADD) and that activated caspase- 8 induces apoptosis, we further used specific siRNA to silence FADD expression and assessed the cell viability. We found that FADD silencing rescues IFN- $\gamma$ induced reduction of cell viability (Figure 3D). Taken together, these data suggest that IFN $-\gamma$-induces apoptosis in H322M and H226 lung cancer cells via a caspase-8- and death receptor-dependent mechanism.

The induced expression and activation of IDO by IFN- $\gamma$ is associated with cell death in H322M and H226 cells

Indoleamine 2,3-dioxygenase (IDO) is the first and rate-limiting enzyme of tryptophan catabolism (Fujigaki et al., 2012; Sagan et al., 2012). Recent studies have reported that IFN- $\gamma$ can induce the expression of IDO in many types of human tumors, and IDO activation is responsible for the antiproliferative action of IFN- $\gamma$ in some cancer cell lines (de la Maza and Peterson, 1988; Ozaki et al., 1988). In this study, our data also indicated a marked elevation of IDO protein (Figure 4A) and RNA expression (Figure 4B) and an increase in IDO enzymatic activity (Figure 4C) in H322M and H226 lung cancer cells following $10 \mathrm{ng} /$ ml IFN- $\gamma$ treatment. However, the IFN- $\gamma$-treated H322M cells exhibited higher IDO expression and activity than did IFN- $\gamma$-treated H226 cells. These data were consistent with the Figure 1 and Figure 2 cell viability and apoptosis results. To confirm the role of IDO in IFN- $\gamma$-induced apoptosis, H322M and $\mathrm{H} 226$ cells were pretreated with the IDO-inhibitor 1-methyl-tryptophan (1-MT) or L-tryptophan, followed by IFN- $\gamma$ treatment for $96 \mathrm{~h}$. As shown in Figure 5, the addition of 1-MT or L- tryptophan significantly decreased the IFN- $\gamma$-induced reduction in cell viability (Figure 5A), apoptosis (Annexin V+/PI-) (Figure $5 \mathrm{~B}$ ), loss of mitochondrial membrane potential
$(\Delta \psi \mathrm{m})$ (Figure $5 \mathrm{C})$ and cleaved forms of caspase -8, -9, -3 and PARP expression (Figure 5D and 5E) in these two cell lines. Thus, these results suggest that IDO enzymatic activity plays an important role in IFN- $\gamma$-induced $\mathrm{H} 322 \mathrm{M}$ and $\mathrm{H} 226$ cell apoptosis.

IDO enzymatic activity participates in IFN- $\gamma$-triggered DR5 expression in H322M and H226 cells

Our results in Figure 3B demonstrated that IFN- $\gamma$ can induce Fas, DR4 and DR5 expression, in H322M and $\mathrm{H} 226$ cells. Therefore, we further examined whether IDO is involved in IFN- $\gamma$-induced death receptor expression in $\mathrm{H} 322 \mathrm{M}$ and $\mathrm{H} 226$ cells. As illustrated in Figure 6A and 6B, 1-MT and L-tryptophan could significantly repress IFN- $\gamma$-induced DR5 expression without significantly affecting Fas and DR4 expression, therefore suggesting that IDO enzymatic activity plays a key role in modulating IFN- $\gamma$-induced death receptor DR5 expression.

\section{Discussion}

IFN- $\gamma$ is confirmed to possess immune-activating properties and hence is proven to have anti-cancer effects in vivo (Wakita et al., 2009; Hayakawa et al., 2011, Yuan et al., 2014). In addition, recent studies also have indicated that IFN- $\gamma$ has the ability to directly inhibit cancer cell growth (Tate et al., 2012; Liu et al., 2012; Jin et al., 2013; Zhao et al., 2013; Wang, 2014); however, the mechanism remains unclear. Our present study demonstrated that the FADD/caspase $8 / \mathrm{tBid} /$ mitochondria pathway plays an important role in IFN- $\gamma$-induced apoptosis in the NSCLC cell lines $\mathrm{H} 322 \mathrm{M}$ and $\mathrm{H} 226$. Notably, our results also demonstrated for the first time that IDO enzymatic activity plays a significant role in the IFN- $\gamma$-induced apoptosis and death receptor 5 (DR5) expression in NSCLC cells.

Recently, IDO enzymatic activity has been reported to be associated with apoptosis in many types of cells. Two possible mechanisms of apoptosis are proposed: 1) depletion of tryptophan (de la Maza and Peterson, 1988; Ozaki et al., 1988; Lee et al., 2002; Platten et al., 2012) and 2) production of toxic tryptophan metabolites in the kynurenine pathway, such as kynurenines and 3-hydroxyanthranilic (3-HAA) (Morita et al., 2001; Fallarino et al., 2003; Mailankot et al., 2009; Lee et al., 2010; Mailankot and Nagaraj, 2010; Song et al., 2011; Hou et al., 2014). In this study, we demonstrated that the addition of either the IDO inhibitor 1-MT or L-tryptophan could decrease IFN- $\gamma$-induced reduction of cell viability (Figure 5A) and apoptosis (Figure 5B-E). Therefore, we suggested that IDO-mediated tryptophan depletion rather than the production of toxic tryptophan metabolites plays a more important role in the anti-NSCLC cancer effect of IFN- $\gamma$, as many studies have indicated that degradation of excess L-Trp via IDO leads to the production of large amount of various types of tryptophan metabolites.

However, these different susceptible effects of tryptophan metabolite-induced apoptosis between H322M and H226 cancer cells and other sensitive cells such as $\mathrm{T}$ cell or lens epithelial cells may be explained by previous study demonstrated that significant apoptosis of thymocytes and T lymphocytes cells was evident at 10 


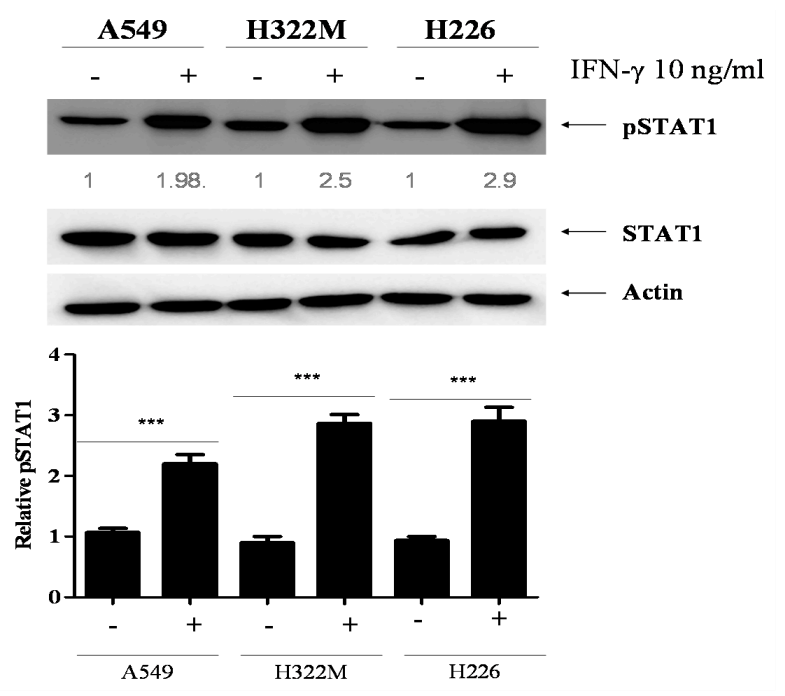

Supplemental Figure 1. IFN- $\gamma$ induced STAT1 phosphorylation in A549, H322M and $\mathrm{H} 226$ cells. Cells were treated with $10 \mathrm{ng} / \mathrm{ml} \mathrm{IFN-} \gamma$ for $15 \mathrm{~min}$. Total cellular protein was extracted, and the phosphoand non-phospho-STAT1 expression was determined by western blot analysis. The bands were analyzed by Image J and normalized to actin. The means $\pm \mathrm{SD}$ of the three independent experiments are presented in the bar graph. ${ }^{* * *} p<0.001$ compared with the PBS-treated group.

$\mu \mathrm{M}$ 3-HAA and QUIN, whereas apoptosis of macrophages or dendritic cells required $>10$-fold higher concentrations (Fallarino et al., 2002).

In this study, we observed that inhibition of IDO activity by 1-MT or L-tryptophan suppressed DR5 expression but did not affect the expression of DR4 and FAS in IFN- $\gamma$-treated H322M or H226 cells (Figure $6 \mathrm{~A})$. To our knowledge, no previous study has reported the relationship between IDO activation and death receptor expression. Some studies have reported that certain intracellular molecules can selectively affect the expression of different death receptors. For example, inhibition of p53 expression affects the expression of DR5 but not that of DR4 in myeloma cells (Surget et al., 2012). Thus, further clarification on the mechanism underlying IDO activity-regulated DR5 expression and further research is still needed.

Our results in Figure 4 result demonstrated that IFN- $\gamma$ can increase IDO expression and activity in A549 and H322M to a greater extent than in H226 cells. The interaction of IFN- $\gamma$ with its cell surface receptor leads to the activation of JAK1 and JAK2 (phosphorylation), which in turn phosphorylates and activates the STAT1 molecules (Chen et al., 2011). In addition, the JAK-STAT1 pathway was also demonstrated to play a critical role in IFN- $\gamma$ induced IDO expression in several cell types (Chon et al., 1996). However, our result demonstrated that IFN- $\gamma$ induced comparable STAT 1 activation among three cells cultured under optimal growth conditions (Supplemental Figure 1). Thus, this research remains unable to explain the diverse reactions to IFN- $\gamma$-induced IDO expression and apoptosis among different NSCLC cells and requires further study.
IDO activation appears to play a role in the suppression of adaptive $\mathrm{T}$-cell-mediated immunity by inducing the apoptosis of T cells (Lee et al., 2002; Fallarino et al., 2002), Treg induction (Sun et al., 2011), and the downregulation of MHC class I ( $\mathrm{Li}$ et al., 2004). Therefore, determining the differences in the mechanisms of IDO-induced direct growth inhibition of tumor cells and IDO-induced suppression of adaptive immunity is also an important area of study in the future for the application of IFN- $\gamma$ in clinical practices against cancer.

In summary, our findings demonstrated that the proliferation of H322M and H226 NSCLC cells was reduced by IFN- $\gamma$ treatment through the induction of IDO enzymatic activity and the activation of the caspase-8/ tBid- and mitochondria-dependent apoptotic pathways. These data provide new insights into the molecular mechanisms underlying IFN- $\gamma$-mediated NSCLC cell death and may provide an efficacious therapy for patients harboring NSCLC.

\section{Acknowledgements}

TW Chung and KT Tang contributed equally to this work. This study was supported by grants from TCVGHNCHU1027608.

\section{References}

Bray F, Cancer, I.A.f.R.o (2014). Globocan 2012: Estimated cancer incidence, mortality and prevalence worldwide in 2012.

Chen J, Hou J, Zhang J, et al (2012) Atorvastatin synergizes with IFN- $\gamma$ in treating human non-small cell lung carcinomas via potent inhibition of RhoA activity. Eur J Pharmacol, 682, $161-70$

Chen SC, Lin YL, Huang B, (2011) Salvianolic acid B suppresses IFN- $\gamma$-induced JAK/STAT1 activation in endothelial cells. Thromb Res, 128, 560-4

Chon SY, Hassanain HH, Gupta SL (1996). Cooperative role of interferon regulatory factor 1 and $\mathrm{p} 91$ (stat1) response elements in interferon-gamma-inducible expression of human indoleamine 2,3-dioxygenase gene. J Biol Chem, 271, 17247-52.

de la Maza LM, Peterson EM (1988). Dependence of the in vitro antiproliferative activity of recombinant human gammainterferon on the concentration of tryptophan in culture media. Cancer Res, 48, 346-50.

Fallarino F, Grohmann U, Vacca C, et al (2002). T cell apoptosis by tryptophan catabolism. Cell Death Differ, 9, 1069-77.

Fujigaki H, Seishima M, K Saito (2012). Posttranslational modification of indoleamine 2,3-dioxygenase. Anal Bioanal Chem, 403, 1777-82.

Guo Y, Wang G, Gao WW et al (2012) Induction of apoptosis in glioma cells and upregulation of Fas expression using the human interferon- $\beta$ gene. Asian Pac J Cancer Prev, 13, $2837-40$

Hagiwara K, Kobayashi K (2013). Importance of the cytological samples for the epidermal growth factor receptor gene mutation test for non-small cell lung cancer. Cancer science, 104, 291-7.

Hayakawa Y, Sato-Matsushita M, Takeda K, et al (2011). Early activation and interferon- $\gamma$ production of tumor-infiltrating mature cd27high natural killer cells. Cancer science, 102, 1967-71. 
Hong M, Jiang Z, Zhou YF (2014). Effects of thermotherapy on th1/th2 cells in esophageal cancer patients treated with radiotherapy. Asian Pac J Cancer Prev, 15, 2359.

Hong S, Kim HY, Kim J, et al (2013). Smad7 protein induces interferon regulatory factor 1-dependent transcriptional activation of caspase 8 to restore tumor necrosis factorrelated apoptosis-inducing ligand (trail)-mediated apoptosis. J Biol Chem, 288, 3560-70.

Hou W, Huang G, Cao X, (2014) Suppression of experimental autoimmune glomerulonephritis by tryptophan. J Nephrol, 27, 19-28.

Jin CG, Chen XQ, Li J, et al (2013). Moderating effects and maintenance of lung cancer cellular immune functions by CIK cell therapy. Asian Pac J Cancer Prev, 14, 3587-92.

Kluck RM, Bossy-Wetzel E, Green DR, et al (1997). The release of cytochrome c from mitochondria: A primary site for bcl-2 regulation of apoptosis. Science, 275, 1132-6.

Lee GK, Park HJ, Macleod M, et al (2002). Tryptophan deprivation sensitizes activated $\mathrm{t}$ cells to apoptosis prior to cell division. Immunology, 107, 452-60.

Lee SM, Lee YS, Choi JH, et al (2010) Tryptophan metabolite 3-hydroxyanthranilic acid selectively induces activated $\mathrm{T}$ cell death via intracellular GSH depletion. Immunol Lett, 132, 53-60

Li H, Zhu H, Xu CJ, et al (1998). Cleavage of bid by caspase 8 mediates the mitochondrial damage in the fas pathway of apoptosis. Cell, 94, 491-501.

Li Y, Tredget EE, Ghahary A (2004). Cell surface expression of mhc class $\mathrm{i}$ antigen is suppressed in indoleamine 2,3-dioxygenase genetically modified keratinocytes: Implications in allogeneic skin substitute engraftment. Hum Immunol, 65, 114-23.

Liu RY, Zhu YH, Zhou L, et al (2012) Adenovirus-mediated delivery of interferon- $\gamma$ gene inhibits the growth of nasopharyngeal carcinoma. J Transl Med. 10, 256.

Mailankot M, Nagaraj RH (2010). Induction of indoleamine 2,3-dioxygenase by interferon-gamma in human lens epithelial cells: Apoptosis through the formation of 3-hydroxykynurenine. Int J Biochem Cell Biol, 42, 1446-54.

Mailankot M, Staniszewska MM, Butler H, et al (2009). Indoleamine 2,3-dioxygenase overexpression causes kynurenine-modification of proteins, fiber cell apoptosis and cataract formation in the mouse lens. Lab Invest, $\mathbf{8 9}$, 498-512.

Mitsudomi T (2010). Advances in target therapy for lung cancer. Jpn J Clin Oncol, 40, 101-6.

Morita T, Saito K, Takemura M, et al (2001).3-hydroxyanthranilic acid, an 1-tryptophan metabolite, induces apoptosis in monocyte-derived cells stimulated by interferon-gamma. Ann Clin Biochem, 38, 242-51.

Ozaki Y, Edelstein MP, Duch DS (1988). Induction of indoleamine 2,3-dioxygenase: A mechanism of the antitumor activity of interferon gamma. Proc Natl Acad Sci U S A, 85, 1242-6.

Platten M, Wick W and Van den Eynde BJ. Tryptophan catabolism in cancer: beyond IDO and tryptophan depletion. Cancer Res. 72, 5435-40.

Prior C, Oroszy S, Oberaigner W, et al (1999). Advanced non-small-cell lung cancer: Adjunctive interferon gamma in induction and maintenance therapy. J Cancer Res Clin Oncol, 125, 42-6.

Sagan D, Kocki T, Kocki J, et al (2012). Serum kynurenic acid: Possible association with invasiveness of non-small cell lung cancer. Asian Pac J Cancer Prev, 13, 4241-4.

Sankari SL, Masthan K, Babu NA, et al (2012). Apoptosis in cancer -an update. Asian Pac J Cancer Prev, 13, 4873-78.

Satoh A, Toyota M, Ikeda H, et al (2004). Epigenetic inactivation of class ii transactivator (ciita) is associated with the absence of interferon-gamma-induced hla-dr expression in colorectal and gastric cancer cells. Oncogene, 23, 8876-86.

Smiley ST, Reers M, Mottola-Hartshorn C, et al (1991). Intracellular heterogeneity in mitochondrial membrane potentials revealed by a j-aggregate-forming lipophilic cation jc-1. Proc Natl Acad Sci U S A, 88, 3671-5.

Sun DS, Hu LK, Cai Y, et al (2014). A systematic review of risk factors for brain metastases and value of prophylactic cranial irradiation in non-small cell lung cancer. Asian Pac J Cancer Prev, 15, 1233-9

Song H, Park H, Kim YS, et al (2011). L-kynurenine-induced apoptosis in human nk cells is mediated by reactive oxygen species. Int Immunopharmacol, 11, 932-8.

Sun J, Yu J, Li H, et al (2011). Upregulated expression of indoleamine 2,3-dioxygenase in cho cells induces apoptosis of competent t cells and increases proportion of treg cells. $J$ Exp Clin Cancer Res, 30, 82.

Surget S, Chiron D, Gomez-Bougie P, et al (2012). Cell death via $\mathrm{dr} 5$, but not $\mathrm{dr} 4$, is regulated by p53 in myeloma cells. Cancer Res, 72, 4562-73.

Tajima K, Ito Y, Demachi A, et al (2004). Interferon-gamma differentially regulates susceptibility of lung cancer cells to telomerase-specific cytotoxic t lymphocytes. Int J Cancer, 110, 403-12.

Tao Y, Zhang ML, Ma PC, et al (2012). Triptolide inhibits proliferation and induces apoptosis of human melanoma a375 cells. Asian Pac J Cancer Prev, 13, 1611-5.

Tate DJ Jr, Patterson JR, Velasco-Gonzalez C, et al (2012) Interferon-gamma-induced nitric oxide inhibits the proliferation of murine renal cellcarcinoma cells. Int J Biol Sci .8, 1109-20

Wakita D, Chamoto K, Ohkuri T,et al (2009). Ifn- $\gamma$-dependent type 1 immunity is crucial for immunosurveillance against squamous cell carcinoma in a novel mouse carcinogenesis model. Carcinogenesis, 30, 1408-15.

Wang F-BW (2014). Interleukin-7 enhances the in vivo antitumor activity of tumor-reactive cd8+t cells with induction of ifn-gamma in a murine breast cancer model. Asian Pac J Cancer Prev, 15, 265-71.

Wang N, Wang W, Huo P, et al (2014). Mitochondriamediated apoptosis in human lung cancer a549 cells by 4-methylsulfinyl-3-butenyl isothiocyanate from radish seeds. Asian Pacific journal of cancer prevention: Asian Pac J Cancer Prev, 15, 2133.

$\mathrm{Xu} \mathrm{N}, \mathrm{Wu}$ SD, Wang H, et al (2012). Involvement of foxm1 in non-small cell lung cancer recurrence. Asian Pac J Cancer Prev, 13, 4739-43.

Yuan CH, Yang XQ, Zhu CL, (2014) Interleukin-7 enhances the in vivo anti-tumor activity of tumor-reactive CD8+ T cells with induction of IFN-gamma in a murine breast cancer model. Asian Pac J Cancer Prev, 15, 265-71

Zhao YH , Wang T , Yu GF, et al (2013). Anti-proliferation effects of interferon-gamma on gastric cancer cells. Asian Pac J Cancer Prev, 14, 5513-8.

Zheng DJ, Yu GH, Gao JF et al (2013) Concomitant EGFR inhibitors combined with radiation for treatment of non-small cell lung carcinoma. Asian Pac J Cancer Prev, 14, 4485-94 